\title{
DE REGEDOR A REFUGIADO, O PROTAGONISMO DE DOMINGOS FERNANDES CARAPEBA NO IMPÉRIO ATLÂNTICO HOLANDÊS
}

\author{
FROM REGEDOR TO REFUGEE, THE PROTAGONISM OF \\ DOMINGOS FERNANDES CARAPEBA IN THE DUTCH ATLANTIC \\ EMPIRE
}

DOI: http//dx.doi.org/10.15448/21778-3748.2018.2.27427

Francisca Jaquelini de Souza Viração

Doutoranda em História - DINTER URCA/UFF

jackhistory@gmail.com

\begin{abstract}
RESUMO: Na história do Brasil Holandês, alguns indígenas ganharam notório conhecimento, dentre eles Felipe Camarão e Pedro Poty, e ao lado deles Antônio Paraupaba. Porém um nome, que chegou ao maior cargo que um índio poderia na administração neerlandesa no Brasil, é quase um completo desconhecido, sendo sua biografia até misteriosa para explicar o porquê tanto prestígio entre os seus irmãos potiguaras. Este artigo, fruto das pesquisas de doutoramento em História Social pelo Dinter UFF/URCA sob orientação de Elisa Garcia, busca traçar uma breve biografia deste líder potiguara que foi protagonista dentro do Império Atlântico Holandês até mesmo depois do fim do domínio batavo no Brasil. Pela ausência de fontes suficientes para uma pesquisa mais apurada, se tentará traçar a sua trajetória através da restrita produção historiográfica que o cita e na ampla produção sobre o Brasil Holandês. Para tanto é preciso mergulhar no mundo em que Domingos Fernandes Carapeba foi inserido, o mundo do Império Colonial Holandês no Attântico tinha características semelhantes ao Espanhol e Português, mas também profundas diferenças, que talvez a maior tenha sido a religião. $\mathrm{O}$ protestantismo, neste caso especificamente o calvinismo, criou um ambiente mental muito diferente do católico, e talvez tenha proporcionado um ar de maior liberdade entre as nações que o abraçou.
\end{abstract}

PALAVRAS - CHAVES: Carapeba; Protagonismo; Brasil Holandês.

ABSTRACT: In the history of Dutch Brazil, some indigenous people gained notorious knowledge, among them Felipe Camarão and Pedro Poty, and next to them Antônio Paraupaba. But a name, which reached the highest position that an Indian could in the Dutch administration in Brazil, is almost a complete unknown, and his biography is even mysterious to explain why so much prestige among his brethren. This article, the result of $\mathrm{PhD}$ research in Social History by Dinter UFF / URCA under the guidance of Elisa Garcia, seeks to trace a brief biography of this Potiguara leader who was a protagonist within the Dutch Atlantic Empire even after the end of Batavian rule in Brazil. Due to the absence of sufficient sources for a more accurate research, one will try to trace its trajectory through the restricted historiographic production that cites it and in the wide production on the Dutch Brazil. In order to do so, one must immerse himself in the world in which Domingos Fernandes Carapeba was inserted, the world of the Dutch Colonial Empire in the Atlantic had similar characteristics to Spanish and Portuguese, but also profound differences, perhaps the greatest one being religion. Protestantism, in this case specifically Calvinism, created a very different mental environment from the Catholic, and perhaps provided an air of greater freedom among the nations that embraced it.

KEYWORDS: Carapeba; Protagonism; Brazil Dutch 


\section{QUEM FOI DOMINGOS FERNANDES CARAPEBA?}

O pouco que se sabe de Domingos Fernandes Carapeba é que ele foi o líder potiguara da aldeia da Tapissserica, aldeia que sediou o maior encontro de líderes potiguaras durante a ocupação holandesa no Nordeste Brasileiro em 1645. Lá ele foi eleito por cerca de 200 chefes de aldeias aliadas aos holandeses, como regedor - mor da câmara de Goiania, que correspondia a Pernambuco e Itamaracá, juntamente com Pedro Poty da Paraíba e Antônio Paraupaba do Rio Grande.

Após a Capitulação de Taborda de 1654 ele foi um dos que liderou a marcha potiguara rumo à Serra da Ibiapaba no Ceará à fim de se refugiar e se proteger das autoridades lusobrasileiras. A esta altura o outro regedor, Pedro Poty já estava morto desde 1649 quando fora capturado na segunda batalha dos Guararapes, Poty morreria pouco tempo depois de sua captura em 19 de fevereiro de 1649. Após a morte de Poty, Carapeba se torna responsável pelos homens de Poty e também pela capitania da Paraíba, que Poty era regedor.

$\mathrm{Na}$ serra a liderança potiguara traçou um plano para o resgate dos potiguaras e para isto Carapeba embarcou para a Holanda com Antônio Paraupaba, viveu na Holanda por dois anos, após a morte de Paraupaba em 1656 foi enviado para o Caribe, juntamente com a mulher e os filhos de Paraupaba, à fim de se encontrar com o antigo diretor do índios do Brasil Holandês Johannes Listry para auxiliá-lo na produção de açúcar. Lá já se encontrava uma comunidade potiguara que embarcara em 1654, logo após o fim do domínio holandês no Brasil.

Em janeiro de 1657 os estados gerais holandeses discutem uma petição de Carapeba para ir morar na ilha caribenha de Tobago. Para o historiador Marcus Mewesse (MEWESSE, 2003, p. 212) esta petição do líder potiguara teria a intenção de se aproximar o mais próximo possível do Brasil com a finalidade de comandar uma embarcação e deslocar o maior número possível de potiguaras refugiados na Serra da Ibiapaba. A esta altura Carapeba era o único exregedor vivo, ele estava na Holanda quando seu companheiro Antônio Paraupaba suplica aos Estados Gerais Holandeses que enviam navios e socorram os índios refugiados na Ibiapaba.

O plano original era de esperar o socorro holandês por dois anos. Paraupaba discursou em 1654 e depois de dois anos em 1656 e morre sem vê seu plano concretizado. Carapeba parece ter pressa de resgatar seus irmãos no Ceará, já que em janeiro de 1657 pede para mudar de ilha, infelizmente não se sabe mais dele depois desta data, porém seu protagonismo parece evidente, mesmo com tão pouca fonte acerca deste líder potiguara. 


\title{
O "IMPÉRIO CALVINISTA HOLANDÊS NO ATLÂNTICO"
}

A historiografia sobre o Brasil Holandês no Brasil é vasta, desde o clássico Tempo dos Flamengos de José Gonçalves de Mello, passando pelas obras de Evaldo Cabral de Mello, até a mais recente produção de Ronaldo Vainfas. Para este artigo é preciso analisar o relacionamento entre indígenas, aqui especificamente os potiguaras e os holandeses, a influencia da religião protestante, para se compreender como os potiguaras atuaram e passaram a pensar e agir pela ótica dos colonizadores. Sobre o relacionamento entre potiguaras e holandeses é preciso partir do ponto de que estes últimos precisavam dos primeiros. José Gonçalves de Mello faz menção da preocupação de Nassau e da WIC (Companhia das Índias Ocidentais) em manter a simpatia dos índios:

\begin{abstract}
Durante todo o período da dominação holandesa no Brasil, uma das preocupações mais constantes de seu governo foi a de atrair e conservar a amizade dos brasilianos - assim chamados os tupis - e dos tapuias. Nassau reconheceu a importância de tais aliados e não se descuidou de procurar a sua amizade. Veremos como, mesmo na Holanda, não deixou de lhes enviar presentes e escrever-lhes cartas. No seu relatório de 1644 diz que "da amizade dos índios depende em parte o sossego e a conservação da colônia do Brasil e que se tendo isto em vista deve-se lhes permitir conservar a sua natural liberdade, mesmo aos que no tempo do rei da Espanha caíram ou por qualquer meio foram constrangidos à escravidão, como eu próprio fiz, libertando alguns." (...) Nassau aqui não fez senão repetir a opinião de seus predecessores e reiterar o ponto de vista do Conselho dos XIX. Se, afinal de contas, nem sempre a política de aproximação e amizade com os índios foi estável, disto não se deve culpar o governo holandês, mas os seus prepostos, os commandeurs, os encarregados das aldeias, os exploradores que contratavam o serviço dos índios; enfim, segundo palavras de Gedeon Morris de Jonge, pela "diabólica cobiça da inconstante riqueza" foram os índios brutalizados, conservados e mesmo vendidos como escravos. Não obstante tudo isto, o que nos mostram os documentos é que a política da Companhia foi sempre a de manter a todo o custo a amizade dos índios. Para isto empregou o serviço de pessoas dedicadas e que se sentiam perfeitamente à vontade entre eles. (MELLO, 2007, p. 210-211).
\end{abstract}

Manter um bom relacionamento com os índios era crucial para a estabilidade e governabilidade do Brasil Holandês. O contexto em que os holandeses aportaram em terras brasileiras, era um contexto de guerra com os espanhóis, guerra que Charles Boxer, chamou de a verdadeira primeira guerra mundial. Aqui tinham que desestruturar um sistema de governabilidade já montado e consolidado na dinâmica colonial. Para tanto tiveram que recorrer à política de alianças com inimigos em comuns dos portugueses, neste caso os potiguaras. Marcus Meuwese em sua tese de doutorado intitulada "For the peace and well-being of the 
country": intercultural mediators and dutch-indian relations in New Netherland and Dutch

Brazil, 1600 - 1664, trabalha com a ideia de que aqui os holandeses foram mais bem sucedidos com os índios por causa do que chama de dependência mutua.

In explaining why Poty and Paraupaba were able to expland their influence as intercultural mediators, I suggest that Dutch imperial policies as well as frontier conditions in Brasil contributed to their success. Instead of as antagonistic relationship between natives and newcomers in mid - Atlantic North America., Tupi - Dutch relations in Brazil were shaped by mutual dependency. While the Dutch West India Company (WIC) needed the Tupis as military force and workers in the colonial economy, many Tupis welcomed the Dutch invaders as highly useful allies in the Tupis struggle against Portuguese colonialism. These mutual needs subsequently facilitated the rise of Poty and Paraupaba as mediators between the Dutch and the Tupis. At the same time, relations between the Tupi and the Dutch were loyal supporters of the WIC, they never deemed themselves subjects of the Dutch colonial order. Instead, the Tupi mediators primarily viewed the alliance with the Dutch as an opportunity to promote Indian autonomy from European colonialism. For all their usefulness as skilful and reliable negotiators, Poty and Paraupaba were therefore never fully trusted by Company officials. (MEWESE, 2003, p. $151-152)$.

É esta dependência mutua que cria as condições específicas para a participação potiguara na burocracia do Estado Holandês no Brasil. E esta possibilidade é uma oportunidade única no contexto das políticas coloniais da América, de uma possível, nem que seja limitada autonomia indígena. Sem estas condições específicas a Assembleia Indígena de 1645 não poderia ter ocorrido, afinal ela se reuniu para analise, debate e aprovação de uma lei vinda da Holanda sobre a liberdade indígena. Meuwese também destaca que a religião protestante foi um dos elementos cruciais que facilitaram e reforçaram sua aliança.

The willingness of the Potiguars to establish an alliance with the Dutch was also expressed by conversion of some Brazilian Indians to Protestant Christianity. According to the De Laet, the Potiguars had "been instructed in the principles of the Christian religion" during their stay in the Republic. Although it is impossible to reconstruct the specific religious motivations of the Potiguars for embracing Dutch Calvinism due to a lack of sources, for the Indians visiting the Republic adopting the public religion of their host was an important way of strengthening bonds with their Dutch allies. Since the Potiguars, six of whom had baptismal names, readily identified the Portuguese with Catholicism, the Potiguars must have seen the theologically and ritualistically different Calvinistic religion as closely associated with the Dutch and the WIC. Some Potiguars may also have adopted Protestantism in an effort to tap into the perceived military and technological power of the Dutch. Like other European powers, the Dutch probably also attempted to impress foreign visitors with the military and economic might of the Dutch by taking their guests to military installations or to commercial towns. Dutch authorities were greatly impressed by and hopeful about the education of the 
Potiguars and their interest in Protestant Christianity. The WIC alliance with the Potiguars was considered so useful for the Dutch that stadholder Frederick Hendrik (1584 - 1647) had hung a painting in his palace in The Hague that depicted the friendly encounter between the Potiguars and the Dutch in Paraíba in 1625. This now lost painting was displayed with other thematic paintings celebrating Dutch power in the great hall of the palace to impress domestic and foreign visitors with the recent successes of Dutch overseas expansion and prominence on the world stage. Similarly, for Dutch Protestants, the Indian Interest in Calvinism was strong evidence that non Christian people rejected Catholicism and instead embraced the "true Christian religion". Realizing the great potential of the Potiguars envoys to function as missionaries to their own people, the Heeren XIX subsequently supported a plan to prepare the Brazilian Indian envoys for a career as Calvinist catechist. In 1628, the WIC reportedly informed stadholder Frederik Hendrik that it was training some of the Potiguars as missionaries in the Republic. (MEUWESE, 2003, p. 89 - 90)

É importante destacar o fato da importância da absorção e vivência da cosmovisão reformada. Na obra Rubro Veio: o imaginário da restauração pernambucana. Evaldo Cabral de Mello rebate a ideia que um possível sentimento nacional teria sido construído nas guerras holandesas, como defendiam os criadores do mito do Brasil Holandês no século XIX. Para o autor pernambucano, os luso-brasileiros desenvolveram uma repugnância ao herege invasor, portanto para rebater a ideia que o republicanismo holandês influenciou de alguma forma os revolucionários luso-brasileiros do século XVII, Mello assegura:

As fontes históricas induzem a conclusão diferente: a convivência com os batavos transmitira aos luso-brasileiros da capitania uma insuperável repugnância pela sua cultura, religião, estilos de vida, reativando seus preconceitos de católicos e de monarquistas. Por conseguinte, não deixa de ser irônico que o elogio do domínio holandês pelo nativismo oitocentista tenha partido dos descendentes dos que outrora tinha assumido atitude de inflexível rejeição a toda espécie de influência batava, de modo a impermeabilizar-se à influência dos hereges. Os luso-brasileiros encararam invariavelmente suas relações com os batavos em termos de incompatibilidade radical, que hoje diríamos cultural, razão pela qual enxergar-se na restauração pernambucana os pródomos da consciência nacional brasileira soa a anacronismo (MELLO, 1997, p. 302).

Este projeto defende que somente os reformados, ou aqueles que tinham absorvido a cosmovisão reformada teriam condições de pensar através da livre consciência, da liberdade individual. Por que naqueles tempos, somente as sociedades protestantes, ou somente os protestantes criaram condições para tal. Sobre a questão da relação entre religião e a ideia de liberdade individual no Brasil Holandês, Ronaldo Vainfas, na obra Jerusalém Colonial, assevera a enorme diferença entre a liberdade religiosa no mundo neerlandês e no mundo ibérico. 
No capítulo I, intitulado "A Jerusalém do Norte", no ponto um, "A Holanda que recebeu os judeus", Vainfas faz uma breve narrativa da formação da República Holandesa, dentro de seu contexto de guerra religiosa de independência contra a Espanha. O referido autor narra a crise político-religiosa com os arminianos, e destaca que, apesar disto, a Holanda jamais teve algo parecido como o Tribunal do Santo Ofício, apesar de ser um estado confessional. O autor afirma ser o calvinismo o fundamento da identidade política da República, citando as Institutas de Calvino e o Catecismo de Heildelberg como suas grandes referências doutrinárias (VAINFAS, 2010).

Em uma tese de doutorado, orientada pelo referido autor, intitulada $O$ leme espiritual do navio mercante, de Maria Aparecida de Araújo Barreto Ribas, a mesma assevera a importância da palavra escrita para a formação de uma mentalidade religiosa completamente diferente entre os potiguaras reformados.

Nada mais claro: para alcançarem maturidade religiosa, necessitavam de educação. Sempre de mais educação. Essa necessidade aparece colocada exaustivamente nos documentos neerlandeses, especialmente nos da Igreja Reformada. Em todas as ocasiões em que discutiram a catequese indígena, afirmavam a necessidade de mais professores para a alfabetização indígena, a fim de inculcar-lhes solidamente os preceitos da fé reformada. Seja nas reuniões de Classe, nas reuniões do Governo, nas cartas à Igreja na pátria, às Câmaras das Províncias, nas cartas a particulares, faziam coro os missionários reformados: "dar maior educação aos brasileiros." (RIBAS, 2007, p. 171).

O destaque à educação se dá pelo fato de que a permissão de leitura da Bíblia e de outros textos religiosos do protestantismo reformado da época possibilitavam aos índios, teoricamente, desenvolver pensamento político. No livro intitulado A Bíblia Inglesa e as Revoluções do séc. XVII, Christopher Hill afirma que, mesmo sem a base política de um Rousseau (fazendo uma comparação com a Revolução Francesa), os ingleses foram capazes de fazer sua revolução baseada em textos bíblicos, chegando a afirmar a existência de uma Revolução Bíblica.

Não deveríamos pensar na Bíblia apenas como um livro a ser lido, ou sobre o qual deve ser ouvido. Ela estava em toda parte, na vida dos homens, mulheres e crianças. Não somente nos cultos dos quais todos deveriam participar, mas igualmente nas baladas que entoavam e no meio em que circundava. (...) A Bíblia era, portanto, onipresente em quase todas as casas. Mas às casas devemos acrescentar as cervejarias, que junto com as igrejas, eram os principais centros da vida comunitária. (HILL, 2010, p. 59).

A Bíblia não era apenas um livro religioso, lido em uma liturgia de culto religioso, mas onipresente na vida comunitária dos protestantes. Hill destaca a importância da Bíblia para a mudança de comportamento dos ingleses em relação às posturas políticas e econômicas da 
época. Claro que não a destaca como a única fonte destas mudanças, mas seu papel e sua leitura com "olhos protestantes" foram cruciais para tais mudanças ocorridas na Inglaterra.

É preciso que estejamos conscientes de certos anacronismos quanto a este ponto. Dizer que a política e a economia eram discutidas usando como referência a Bíblia pode nos levar a supor que os homens e as mulheres da época eram influenciados pela "religião", ao contrário do que acontece com os homens e mulheres do nosso século (...) Devemos diferenciar a linguagem bíblica utilizada pelos homens de suas ações concretas, que precisam ser descritas hoje em termos seculares. Entretanto, é, ao mesmo tempo, importante que evitemos a armadilha oposta, de supormos que a "religião" era usada como um "disfarce" para encobrir motivos seculares "reais". Este pode ter sido o caso de alguns poucos indivíduos, mas para a maioria dos homens e mulheres a Bíblia foi o ponto de referência de todo o seu pensamento. (HILL, 2010, p. $54-55)$.

Outro historiador fundamental para o período é Frans Leonard Schalkwijk, que em sua obra clássica, Igreja e Estado no Brasil Holandês, trabalha de forma muito aprofundada o surgimento do calvinismo na Holanda, a organização de sua república, a origem da WIC, as razões pela escolha do nordeste brasileiro, as missões indígenas e seu papel na estruturação do Brasil Holandês.

Porém toda esta cosmovisão reformada era empregada em um contexto de colonização e em um país que já fora evangelizado antes. Desta feita é preciso fazer considerações sobre a dinâmica colonial e a religião na colônia. Que Brasil os holandeses encontraram? E como esses holandeses viam o Brasil que encontraram? Não se pode falar de visões sobre a colônia sem se reportar a Sérgio Buarque de Holanda, em sua construção do fantástico, do Brasil como o Paraíso para portugueses católicos, e também um pouco mais que Paraíso para os protestantes. Em Visões do Paraíso, afirma:

...a demanda do Paraíso entre os descobridores ou conquistadores latinos, e acentuando o papel, nesse sentido, dos sacerdotes católicos que compunham aqueles homens, nota o autor como vinham eles animados pela crença em um Éden que generosamente se oferecia, e estava "só à espera de ser ganho" (merely waiting to be gained), tanto que já Colombo anunciara ao seu soberano que o tinha achado quase com certeza. Em contraste com eles, os peregrinos puritanos, e depois os pioneiros do Oeste, vão buscar nas novas terras um abrigo para a Igreja Verdadeira e perseguida, e uma "selva e deserto", na acepção dada a estas palavras pelas santas escrituras, que através de uma subjugação espiritual e moral, mais ainda do que pela conquista física, se há de converter no Éden ou Jardim do Senhor. (HOLANDA, 2000. p. XIII).

A religião na colônia portuguesa na América é um empreendimento estatal, seja ele católico ou protestante. Ao contrário das iniciativas particulares como a colônia quacker da 
Pensilvânia, isto não significou um maior purismo religioso por parte da população colonizada, na verdade é a religiosidade da colônia que lança as bases para o sincretismo religioso que vemos hoje no Brasil, como assevera Laura de Mello e Souza em O Diabo e a Terra de Santa Cruz. Esta característica faz com que o trabalho dos pastores holandeses dobrasse, já que sincretismo religioso sempre foi algo estranho aos protestantes.

Em Heresias dos índios, Ronaldo Vainfas relata como os indígenas se apropriaram da própria religiosidade católica, a qual foram obrigados a aceitar, para criar sua própria forma de resistência. Misturaram elementos católicos com o animismo para resistir ao processo de colonização. Apesar dos potiguaras não terem feito sincretismo religioso, e nem resistido à colonização, já que faziam parte do Estado, esta obra mostra claramente que nossos indígenas eram capazes de criarem outras formas de resistência, além da armada, e usar a religião para tal.

Falar em idolatrias insurgentes significa referir-se, antes de tudo, a movimentos sectários, animados por mensagens francamente hostis ao europeu, sobretudo à exploração colonial e ao cristianismo, não obstante algumas delas tenham assimilado, em maior ou menor grau, ingredientes do catolicismo que tanto rejeitavam. Na dinâmica de tais idolatrias, organizadas em função da defesa das tradições ameríndias, as atitudes de resistência oscilavam da "guerra cósmica" à luta armada - mais factível esta última quando os movimentos ocorriam em regiões de fronteira, ou seja, em áreas incompleta ou precariamente dominadas pelos colonizadores. (VAINFAS, 2005 , p. $33-34)$.

Além de tudo isto é preciso compreender como eram as relações entre portugueses e indígenas anteriormente à expansão colonial holandesa no Brasil. A escravidão dos ameríndios era um aspecto central na empresa colonial portuguesa no Brasil. Este aspecto é profundamente abordado por John Manuel Montero em Negros da Terra, obra em que o autor afirma sobre a questão da escravidão dos indígenas na colonização portuguesa:

Nesse sentido, a escravidão era justificada pela prática tradicional de dominação dos infiéis que conscientemente haviam rejeitado a fé católica, fato relevante na medida em que aderia aos princípios da guerra justa, estabelecidos pelos papas e reis católicos. Assim, as "nações bárbaras", infiéis e levantadas em armas contra os cristãos, teriam que ser submetidos à força. Igualmente, porém, mesmo os índios "mansos", os que "por sua livre vontade procurarem o prêmio da Igreja", teriam de trabalhar para os colonos, não como escravos legítimos, mas "por seus interesses." (...) Em suma, para o autor destas observações e para muitos de seus contemporâneos, a necessidade absoluta da escravidão arraigava-se na convergência entre a mentalidade colonial referente ao trabalho e o anseio de prosperidade que dava sentido à Colônia. Assim, sustentava Carvalho, os paulistas não podiam abrir mão do gentio, porque isto, além de eliminar os benefícios proporcionados pela

Oficina do Historiador, Porto Alegre, EDIPUCRS, v. 11, n. 2, jul./dez. 2018, 
capitania reduziria os próprios a um estado selvagem, no qual se veriam obrigados a viver à moda gentílica, fato que já se observava entre os estratos inferiores da sociedade colonial. Assim, a questão da escravidão indígena era muito mais complexa do que mero debate moral em torno da legitimidade do cativeiro. De fato, a escravidão tocava no próprio centro nervoso do colonialismo português, onde as políticas públicas e os interesses privados conspiravam para produzir benefícios mútuos às custas dos povos ameríndios e africanos (MONTERO, 2009, p. 135 - 136).

Para este artigo é crucial compreender as diferenças de tratamento dos indígenas por parte dos portugueses e dos holandeses. Como já fora dito anteriormente, estes últimos necessitavam da aliança com os potiguaras e também com os tapuias (esta apenas aliança política e militar, sem envolver religião). Para os potiguaras, a liberdade era um fato crucial para sua aliança com os holandeses, como afirma Manuela Carneiro da Cunha em História dos indios do Brasil:

Não é o caso de buscar definir aqui as razões pelas quais parte dos índios se aliou aos holandeses, sequer de avaliar se a aliança estabelecida resultou positiva para os primeiros, o que tem sido negado (MELLO, 1979: 207). Em relação a um aspecto, contudo parece haver consenso, e este é relevante para o entendimento da aliança, ou seja, a liberdade religiosa e a tolerância que prevaleceram sob o governo de Nassau (HEMMING, 1978: 289; REGNI, 1988, VOL I: 70), das quais os grandes beneficiários teriam sido os judeus e os índios (CUNHA, 2002, p. 439).

Também é preciso ter em mente quem eram os holandeses que aqui vieram. Envoltos em uma Guerra Político-Religiosa com a Espanha, guerra esta que era apenas parte de um conflito maior que envolveu toda a Europa. Os holandeses da primeira metade do século XVII já tinham um forte senso de liberdade individual, e muito mais do que isto, eram o povo da liberdade, e esta liberdade era divina, como afirma Simon Schama em O Desconforto da riqueza:

A crônica histórica forneceu tranquilizadoras provas de que as virtudes estoicas do sacrifício patriótico, incorruptibilidade e magnanimidade sempre estiveram presentes na cultura neerlandesa. No entanto, o que lançou luz mais intensa sobre o espírito do futuro e do passado dos holandeses foi a Bíblia. Tratava-se, necessariamente, do Velho Testamento. Os evangelhos do Novo Testamento eram manifestamente universais no significado e pessoais no tema (pelo menos para um protestante). O Velho Testamento, porém, era escritura patriótica, a crônica de um povo escolhido por Deus para revelar Sua luz ao mundo mediante sua própria história. Com base nas atribuições, vitórias, cativeiros, peregrinações e profecias deste povo - relatadas pela palavra impressa da Bíblia, pela cultura oral do púlpito, pelas dramatizações narrativas do teatro histórico e pelas imagens impressionantes apresentados nas gravuras -, os holandeses conseguiram responder a essas inquietantes perguntas acerca de sua própria identidade. Quem eram eles? Eram os novos/velhos batavos, 
guardiães da waare vrijheid (verdadeira liberdade). Eram hebreus renascidos, filhos da Aliança. De onde vieram? Da escravidão e da idolatria, e por meio do ordálio chegaram à liberdade e à devoção ao Deus único. O que iriam fazer? Revelar ao mundo os desígnos de Deus mediante seu destino nacional e viver com honra, prosperidade e glória, enquanto obedecessem os mandamentos divinos. (SCHAMA, 1992, p. 77).

O calvinismo merece destaque neste artigo, já que os principais acionistas da WIC eram calvinistas, portanto analisá-lo é importante e crucial para compreender o universo mental em que Carapeba foi inserido e que teve que aprender a se adequar dentro da nova estrutura colonial que vivia. Aqui o calvinismo será encarado a partir do conceito de campo de Pierre Bourdieu. Segundo Roger Chartier em palestra proferida na Universidade Federal do Rio de Janeiro intitulada Pierre Bourdieu e a História, Bourdieu entendia campo:

Os campos, segundo Bourdieu, têm suas próprias regras, princípios e hierarquias. São definidos a partir dos conflitos e das tensões no que diz respeito à sua própria delimitação e constituídos por redes de relações ou de oposições entre os atores sociais que são seus membros. (CHARTIER, 2002, p. 140).

E a partir desta concepção de campo é preciso problematizar como o protestantismo foi se configurando como tal. O protestantismo não surgiu em 1517 e nem nos movimentos préreformistas de Huss e Wycliffe, mas quando surge a palavra "protestante. Em 1529, os príncipes alemães declaram um protesto contra a Dieta de Speyer que reafirmava o Édito que Worms, que negava as 95 teses de Lutero. Por já nascer tenso e conflituoso, a categoria campo parece adequar-se para analisar o protestantismo.

Quando a palavra "protestante" é proferida pela primeira vez aos seguidores de Lutero, João Calvino é um jovem estudante de Direito de 20 anos na França, e ainda seria preciso esperar 4 anos para sua adesão definitiva ao movimento reformista. E só 30 anos após o surgimento do termo "protestante" surge o calvinista, quando é criada a Academia de Genebra e sua influência intelectual passa a designar os estudantes que ali passavam.

Em termos teológicos, o que de fato vai definir e diferenciar luteranismo de calvinismo é a postura acerca da eucaristia, porém politicamente ambos pensarão diferente também. Lutero vê uma separação rígida entre a vida do cristão na igreja e como súdito de um Estado, é sua teoria dos dois reinos, que não se encontra em Calvino. Para Kuyper, esta visão de Calvino fez com que o calvinismo tenha tido um caráter mais revolucionário que o luteranismo:

O Luteranismo restringiu-se a um caráter exclusivamente eclesiástico e teológico, enquanto que o Calvinismo coloca sua marca na Igreja e fora dela, sobre cada departamento da vida humana. Por isso, em lugar algum o 
Luteranismo é citado como o criador de uma forma peculiar de vida; até mesmo o nome de "Luteranismo" quase nunca é mencionado; enquanto que os estudantes de História com crescente unanimidade reconhecem o Calvinismo como o criador de uma cosmovisão inteiramente própria. (KUYPER, 2002, p. 29).

O luteranismo tende a ser mais obediente ao Estado, o calvinismo só o é até este não lhe obrigar a pecar, caso contrário, o calvinista não apenas tem o direito, mas o dever de resistir a este Estado, pois deve-se obediência primeiro a Deus. Sob esta perspectiva é que os holandeses calvinistas pegam em armas contra Filipe II. Se sentiam não apenas no direito, mas no dever de resistir. O calvinismo vai ganhando uma vertente política e não apenas religiosa.

Com as guerras de religião, principalmente a Guerra dos 30 anos e a Revolução Inglesa, essa vertente do calvinismo vai ganhando corpo, numa linguagem de Bourdieu, autonomia, e se configurando em um micro-campo. Os holandeses chegaram no Brasil em guerra com a Espanha (a Guerra de independência que também se confunde em uma vertente da Guerra dos 30 anos). Quando estavam consolidando seu domínio no Nordeste, estoura a Revolução Inglesa, e cinco anos depois os potiguaras organizaram sua Assembleia.

Em 1645 praticamente todas as Confissões de fé e catecismos calvinistas haviam sido escritos, mas nenhum documento é mais importante para o calvinismo holandês do que os Cânones de Dort de 1619, e apesar de neste documento não haver nenhuma postura política, as questões que o levam a existir são eminentemente políticas e são centrais na criação da famosa Companhia das Índias Ocidentais, empresa que financia e administra o Brasil Holandês.

Os índios servidores públicos eram pagos por ela. Compreender todas as facetas que a levam a existir é de suma importância para se vislumbrar que tipo de calvinismo político chegou ao Brasil. Charles Boxer, em Os holandeses no Brasil, aponta para a figura de Wilherm Usselinx e para a questão remonstrante como o ponto chave para entender a formação da WIC.

Era Usselincx um ardoroso calvinista, havendo em seus planos forte influência religiosa. Ocorre repetidamente em seus escritos a ideia de transplantar para o Novo Mundo a "verdadeira religião de Cristo", e de combater os erros do papismo anticristão. Embora, como ficou dito, preferisse a ocupação pacífica das regiões não ainda colonizadas da América, com a permissão tácita (ou explícita) da Espanha, compreendeu Usselincx que isso poderia não ser conseguido. Opinava que nesse caso a trégua devia restringir-se à Europa, prosseguindo a luta além da linha equinocial, de modo que, sendo necessário, pudesse a Holanda, a ponta de espada, povoar as suas colônias americanas. (BOXER, 1961, p. 6).

Os partidários de Usselincx eram calvinistas militantes, dentre eles o príncipe Maurício de Nassau. Para os calvinistas, odiar a Espanha era uma questão de orgulho pátrio, já que foram 
eles que articularam a guerra contra a Espanha a fim de conquistarem sua independência reagindo às perseguições religiosas e econômicas (os burgueses, em sua maioria calvinistas, foram submetidos a altos impostos pelo Duque de Alba).

Em 1610, uma congregação de 44 pastores se reuniu para debater questões sobre a soberania de Deus e a liberdade do homem. Seu documento, a Remonstrância, ganhou vários adeptos na igreja reformada, dentre eles, Johan Van Oldenbarnevelt. O mais proeminente pastor da Remonstrância foi Jacob Arminius, mais tarde os remonstrantes ficaram conhecidos como arminianos.

Por tocarem em pontos cruciais para os calvinistas, como o fato de o homem poder perder a salvação e rejeitar ser salvo, visto que sua eleição se deve à presciência de Deus e não à predestinação, graves embates surgiram dentro da igreja reformada. Quando Johan Van Oldenbarnevelt, um diplomata, alinha-se aos remonstrantes, logo os demais que são remonstrantes e membros da Assembleia Geral se configurarão mais como um partido do que um grupo religioso. Como os calvinistas queriam continuar a guerra com a Espanha, os remonstrantes a paz, política e religião rapidamente se misturaram.

Graças à ambígua redação da quarta cláusula do tratado de 1609, a paz estava virtualmente confinada à Europa; mas o partido que a defendia, tendo à frente o venerando estadista Johan van Oldenbarnevelt, utilizava-a como justificativa para pôr de lado os planos ambiciosos de Usselincx. Procuravam os adeptos de Oldenbarnevelt mostrar que a Holanda podia agora obter nos portos espanhóis e portugueses todos os produtos da América, e com muito mais facilidade e segurança do que rumando para o mar das Caraíbas. A oligarquia burguesa que advogava os interesses da Holanda não estava interessada em fundar colônias agrícolas em terras de além-mar, nem tampouco em difundir a "Religião Cristã" entre os "obcecados pagãos" do Novo Mundo. Argumentavam que a Holanda já tinha muito com que comerciar e pelejar nas Índias Orientais, onde a trégua nunca foi posta em execução, dando lugar a que a expansão holandesa fosse acelerada, em detrimento do claudicante "Estado da Índia" português. (BOXER, 1961, p. 6)

Os partidários do príncipe Maurício de Nassau vencem, o Sínodo de Dort reafirma o calvinismo e Johan van Oldenbarnevelt é enforcado e acusado de alta traição, de forma que Usselincx e os calvinistas passam a controlar a WIC. Este é o ambiente carregado da empresa que arquitetou a tomada do Brasil. O ódio ao espanhol, que graças a União Ibérica, desde 1580 era ódio aos espanhóis e portugueses. Pode-se afirmar que o Império Atlântico Holandês tem início com a criação da Companhia Neerlandesa das Índias Ocidentais em 1621, e três anos depois a WIC tentava sua primeira incursão em solo brasileiro. O objetivo era monopolizar o comércio de açúcar no Atlântico. 


\section{OS POTIGUARAS E A ADMINISTRAÇÃO HOLANDESA NO BRASIL}

As relações entre batavos e potiguaras tiveram início em 1625, quando as tropas de Boudewijn Hendrijks, fugidos da primeira tentativa de domínio ao Brasil pararam na Baía da Traição na Paraíba e lá fizeram aliança com a liderança potiguara. Desta aliança embarcaram 13 indígenas, dentre eles Poty e Paraupaba. Carepeba não estava entre eles.

Na Holanda, os potiguaras deram informações valiosas aos pilotos holandeses acerca da geografia do Nordeste e também receberam educação, com a finalidade de conhecerem a cultura holandesa e se converterem ao protestantismo. Receber educação holandesa tinha a finalidade de reforçar os laços entre os dois povos e afirmar mais ainda esta liderança como mediadores culturais que desempenharam várias funções, com o objetivo de conquistar o Nordeste para a República Holandesa. Estas funções são parecidas com as funções que as aldeias desempenhavam:

1. Suporte para a exploração de açúcar;

2. Forte militar;

3. Laboratório protestante.

From the perspective of High Council in Refice, the considerable Tupi population inhabiting the aldeias in Dutch - controlled Brazil was useful for three important purposes. Frist, like the Portuguese before them, the Dutch considered the Tupis a cheap and readily available labor force for the sugar mills and Brazilwood harvesting that dominated the economy of northeastern Brazil. The second purpose that the aldeias served for the Dutch was as an important supplier of auxiliary troops, guides and carriers for the WIC army. (...) The third and final use of the aldeias for the High Council was as an isolated laboratory to civilize the Tupis and convert them to Protestant Christianity. Like the Jesuits before them, the High Council and Dutch Calvinist ministers considered it prudent to concentrate the traditionally mobile Tupi communities in fixed settlements where they could be better taught the ways of Europeans Christian civilization such as monogamous marriages, baptisms, church services, reading, writing, agriculture, and limited number of crafts. Ironically, this goal of civilizing the Tupi in their aldeias was undermined by the purpose of enlisting the Tupi economic and military tasks. (MEUWESE, 2003, p. 153 - 154).

Torna-se nítido que os holandeses tinham propósitos militares, econômicos e sociais nas aldeias. Estes três propósitos eram imprescindíveis para os tais e, sendo em áreas sensíveis, não demoraria muito para gerar conflitos. Índios se rebelaram contra os representantes da WIC, como os do Ceará que até mataram o governador holandês da capitania, Gedeon Moris de Jong. Estes conflitos são naturais, e o fato de existirem é uma prova contundente de que, se houve 
conflitos, é porque os índios também tinham seus interesses em jogo. Desta feita, é adequado acrescentar o nome político antes destas funções. Assim, o Brasil Holandês teve índios com funções político-militares (regedores), político - econômicas (os principais) e cultural-religiosas (mestres - escolas).

O capitão era um funcionário público da República Holandesa, e seu soldo era pago pela Companhia das Índias Ocidentais, como todos os outros funcionários, até mesmo Nassau era pago pela WIC. Sua função era prover a segurança das praças conquistadas e conquistar mais. Pedro Poty, por exemplo, tinha a seu dispor cerca de 200 homens na sua Aldeia, Massurepe na Paraíba.

O cargo de Regedor, que se complementa ao de capitão veio após 1645 com a famosa Assembleia Indígena que ocorreu naquele ano, a qual criava uma espécie de Câmara de Deputados Indígena no Brasil Holandês, onde três regedores foram eleitos para representar os índios no Alto Conselho do Brasil Holandês. Portanto, era um cargo político, que se funde a um militar quando um capitão é eleito regedor.

Principal é um cargo político-econômico: político porque o principal é um cacique, um homem respeitado pela sua tribo; econômico porque era com os principais que os representantes da WIC tratavam quando necessitavam da mão-de-obra indígena. Gaspar Paraupaba, principal dos potiguaras do Ceará, era quem tratava com Mathias Beck, governador do Ceará Holandês, sobre a exploração das possíveis Minas de Prata.

E mestre-escola era um cargo exclusivamente cultural-religioso. A função de um mestre-escola era ensinar a leitura, a escrita e a doutrina reformada. No protestantismo, o crente deve ler a Bíblia, aliás, o Livre-Exame das Escrituras e o direito de ler a Bíblia no vernáculo foi uma das principais reivindicações conquistadas pela Reforma Protestante do séc. XVI, sendo que João Gonçalves e Álvaro Jacó foram os que mais se destacaram nesta função.

Onde Domingos Fernandes Carapeba se encaixa em tudo isto? Infelizmente, o período em que Carapeba aparece na documentação holandesa é curto para tamanho protagonismo deste líder potiguara, somente entre 1645 e 1657. Por enquanto, o que se sabe dele é isto, que foi regedor dos índios de Itamaracá e Pernambuco, que gozava de enorme prestígio entre os indígenas, que viajou à Holanda, foi enviado ao Caribe. Seu prestígio era tão grande que foi a ele, mesmo sem ainda saber falar o neerlandês, que foi entregue a "Carta de liberdade", o documento feito pelo conselho da WIC sobre a liberdade indígena, sobre a qual os potiguaras debateriam em 1645.

Since the candidates nominated by the Tupis had to be approved by the High Council, the Recife councilors reserved the right to turn down Poty and 
Paraupaba. Because of Paraupaba's recent challenge and Poty's earlier behavior, the High Recife councilors had good reasons to avoid placing the two Potiguars in the influential position as regidors. Despite these reasons, they did so place them; at the special council held in Recife from April 10 through 13, 1645, the High Council formally recognized the appointment of both Poty and Paraupaba. Why would the Recife councilors have supported the nomination of these two men in the face of the latter's recent conflicts with the WIC? Ironically, because of their unique familiarity with both the Dutch language and the WIC organization, Poty and Paraupaba remained probably two of the very few Tupi leaders with whom the High Council could efficiently communicate. In addition, realizing that marginalizing Poty or Paraupaba would upset the Heeren XIX, the Recife officials may have sought to avoid a reprimand. Finally, by assigning them to positions that brought the two Potiguar leaders in frequent contact with the High Council, the Recife officials could firmly control the two leaders more firmly. Still, even as they sanctioned the appointments of Poty and Paraupaba, the Recife officials made it clear that they did not fully trust either of the two men. During the special council held in Recife from April 10 through 13, the High Council had the Tupi leaders swear an oath of loyalty to the WIC in return for which they would receive a sealed "Letter of Freedom for the Brazilians," signed by the Heeren XIX, that outlined the new rights and duties of the Tupis. But instead of issuing one letter each to the three Tupi regidors, the High Council handed out only one sealed letter. Neglecting Poty and Paraupaba, the Recife officials provided Domingo Fernandes Carapeba with the "Letter of Freedom for the Brazilians" and specifically instructed him to take good care of it. (MEWESSE, 2003, p. 192 - 193).

Se Domingos Fernandes Carapeba era líder dos potiguaras da aldeia de Tapisserica e se tornou regedor dos índios da Câmara de Goiânia, sua função política era muito acentuada. Depois da morte de Pedro Poty, Carapeba teve seus homens sob sua responsabilidade e também sua câmara, assim a partir de 1649 com a morte de Poty, Carapeba se tornou o líder potiguara mais poderoso, apesar de que o fato de Antônio Paraupaba ter sido educado na Holanda, fazia do regedor do Rio Grande mais influente.

O universo mental em que Carapeba está ajuda a explicar a tamanha confiança depositada nele. Carapeba teve a oportunidade de comparar os dois mundos coloniais, português e holandês e o fato de índios da liderança potiguara embarcarem para a Holanda em 1625 deu-lhe mais incentivo para se inserir no mundo colonial holandês no Brasil. Neste mundo ele é um protagonista, é até um funcionário público da República dos Países Baixos. Sua oportunidade de agir é infinitamente maior do que no mundo colonial português, a mentalidade política criada dentro de um universo calvinista proporcionou as condições para tal dentro da empresa colonial holandesa.

Ele não embarcou em 1625 rumo à Holanda como seus irmãos Poty e Paraupaba, porém se foi eleito regedor da câmara mais importante é por que seu protagonismo acompanhou seus irmãos neste projeto, porém em solo brasileiro, em uma outra perspectiva, a perspectiva da

Oficina do Historiador, Porto Alegre, EDIPUCRS, v. 11, n. 2, jul./dez. 2018, 
espera. Confiar em um projeto de domínio colonial quando se embarca e vê as possibilidades do colonizador é uma coisa, esperar por cinco anos sem nenhuma notícia é outra. Talvez esta virtude tenha feito com que os holandeses confiassem mais em sua lealdade.

Mas notável mesmo é sua lealdade a seu povo, e pelo menos por três vezes teve a oportunidade para demonstrar isto. A primeira foi quando a guerra de resistência luso-brasileira iniciou em 1645, e André Vidal de Negreiros ordenou o enforcamento de 30 lideranças indígenas aliadas aos holandeses e ataques constantes às aldeias aliadas. Carapeba, juntamente com os outros dois regedores buscou proteger seu povo o máximo possível, tanto que o regedor de Pernambuco e Itamaracá conseguiu levar 1500 índios, na maioria mulheres, crianças e idosos para o forte Orange na ilha de Itamaracá (MEUWESSE, 2003, p. 200).

A segunda foi depois do fim do domínio holandês no Brasil, quando participou do plano potiguara de se refugiar na Serra da Ibiapaba no Ceará com o objetivo de esperar o resgate holandês. Ele foi à Holanda junto com Paraupaba para apresentar as condições de seu povo aos Estados Gerais Holandeses na condição de regedor-mor, uma autoridade reconhecida pelo estado holandês. Viu seu companheiro morrer e o resgate não chegar, foi enviado aonde não queria, mas mesmo assim não parou de lutar, ainda insistiu em chegar o mais próximo deles.

\section{CONSIDERAÇÕES FINAIS}

O Brasil Holandês ainda reserva histórias apaixonantes como a de Domingos Fernandes Carapeba, mas muito mais que apaixonantes, revelam o protagonismo indígena. De índios que não devem ser vistos como meras marionetes no jogo político dos impérios coloniais europeus, mas sim como agentes que tinham seus próprios interesses e objetivos e que lutaram com todas as armas possíveis para concretizá-los.

Além disto, proporcionou para as nações indígenas que se aliaram aos batavos três oportunidades novas neste jogo político colonial: 1 - a oportunidade de comparar modelos coloniais; 2 - a oportunidade de tratar um colonizador com um pouco mais de paridade, já que os holandeses necessitavam do apoio indígena; 3 - a oportunidade de conhecer a liberdade individual do universo protestante europeu.

E o conhecimento disto foi decisivo para as decisões tomadas por Carapeba sobre o que seria melhor para seu povo. As pesquisas sobre o papel desempenhado pelos indígenas no Brasil Holandês é um tema clássico na História Indígena e tem contribuído decisivamente para a maior compreensão do papel dos nossos indígenas na história brasileira, talvez nesta breve análise do 
protagonismo do Regedor Domingos Fernandes Carapeba contribua para novas problematizações sobre a temática.

Além disto nos faz pensar, nesta recente crise migratória que o mundo vive, em especial o dilema dos refugiados sírios, o papel dos refugiados ao longo da história, já que Carapeba não deixa de ser um refugiado. Perseguido político e também religioso pelo Império Português, desempenhou papel importante, mesmo no refúgio, e demonstrou vontade inabalável de resistência mesmo quando tudo parecia ter chegado ao fim.

\section{REFERÊNCIAS BIBLIOGRÁFICAS}

BOXER, Richard. Império Marítimo Português. São Paulo: Companhia das Letras, 2002.

CHAUÍ, Marilena. Brasil, mito fundador e sociedade autoritária. São Paulo: Editora fundação Perseu Abramo 2000.

CUNHA, Manuela Carneiro da. História dos índios do Brasil. São Paulo: Companhia das Letras, 2002.

DAVIES, Natalie Zemon. Culturas do Povo: sociedade e cultura no início da França Moderna. Rio de Janeiro: Paz e Terra 1990.

DE CERTAU, Michel. A escrita da História. $2^{\text {a }}$ ed. Rio de Janeiro: Editora Forense Universitária, 2010.

FEBVRE, Lucien. O problema da incredulidade no século XVI, a religião de Rabelais. São Paulo: Companhia das Letras, 2009.

GOMES, Antônio Máspoli de Araújo. Religião, Educação e Progresso, a contribuição do Mackenzie College para a formação do empresariado em São Paulo entre 1870 e 1914. São Paulo: Editora Mackenzie 2000.

GONÇALVES, Regina Célia. Guerra e Açúcares: política e economia na Capitania da Parayba (1585 - 1630). Bauru: Edusc, 2007. 
Os potiguara na Guerra dos Brancos (1630 - 1645).

Disponível em www.ifch.unicamp.br/inb/Textos/RCGoncalves.pdf

GOUVÊA, Ricardo Quadros (org). A verdadeira vida Cristã - João Calvino. São Paulo:

Editora Novo Século, 2000.

GUINZBURG, Carlo. O queijo e os vermes: o quotidiano e as ideias de um moleiro perseguido pela Inquisição. São Paulo: Companhia das Letras, 2001.

HILL, Christopher. A Bíblia Inglesa e as Revoluções do século XVII. São Paulo: Editora Civilização Brasileira, 2003.

O Mundo de Ponta Cabeça. São Paulo: Companhia das, 1987.

O Eleito de Deus. São Paulo: Companhia das Letras 2001.

HOLANDA, Sérgio Buarque de. Raízes do Brasil, Construtores do Brasil. São Paulo: Nova Cultural, 2000.

. Visões do Paraíso. Coleção Grandes Nomes do Pensamento brasileiro. São Paulo - SP, Publifolha, 2000.

KROMMER, Rita. Mathias Beck e a Companhia das índias ocidentais no Ceará. Fortaleza: Editora da UFC, 1994.

KUYPER, Abraham. Calvinismo. São Paulo: Cultura Cristão, 2002.

LEONARD, Émile G. O protestantismo brasileiro, estudo de eclesiologia e História Social. Rio de Janeiro e São Paulo, JUERP e ASTE, 1981.

MAIA, Lígio de Oliveira. Índios de Pernambuco na Genebra dos sertões: o olhar vieiriano sobre os índios hereges - XVII. Cadernos de Estudos Sociais, Recife, Vol 22, n.1, jan/jun 2006. 
MELLO. Evaldo Cabral de. Rubro veio, o imaginário da restauração pernambucana. $2^{\circ}$ ed. Rio de Janeiro: Topbooks, 1997

MELLO, José Antônio Gonçalves de. Tempo dos flamengos: a influência da ocupação holandesa na vida e na cultura do norte do Brasil. 5ªd. Rio de Janeiro: Topbooks 2007.

MENDONÇA, Antônio Gouvêa. Protestantismo no Brasil. Revista USP, São Paulo, SP, m.74, junho/agosto 2007 p. $160-173$.

MEUWESE, Marcus P. "For the Peace and Well-being of the Country": Intercultural Mediators and Dutch-Indian Relations in New Neatherland and Dutch Brazil, 1600- 1664.

Tese de Doutorado defendida na University of Notre Dame, Notre Dame, Indiana, Setembro de 2003. Disponível em:

http://etd.nd.edu/ETDdb/theses/available/etd09272003005338/unrestricted/MeuweseMP0920 03.pdf Acessado em 24/01/2007

MOLLER, Mathias. Ensaio sobre a liberdade do cristão segundo Lutero. Pólemos,

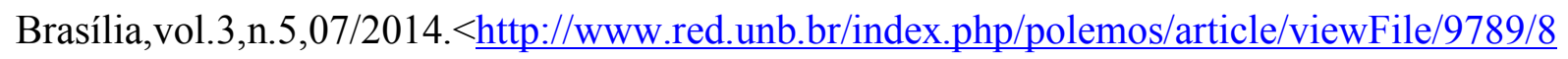
$\underline{265>}$ acesso 20 de Agosto de 2015

MONTERO, John Manuel. Negros da Terra, índios e bandeirantes nas origens de São Paulo. São Paulo: Companhia das Letras, 2009.

RAMINELLI, Ronald. Imagens da Colonização: a representação do índio de Caminha a Vieira. Rio de janeiro: Jorge Zahar, 1996.

. O índio e o renascimento português. Revista de História Social, São

Paulo, USP, ${ }^{\circ}{ }^{1}, 1994$

RIBAS, Maria Aparecida de Araújo Barreto. O leme espiritual do navio mercante: A missionação calvinista no Brasil Holandês (1630 - 1645). Tese de Doutorado defendida na Universidade Federal Fluminense, Niterói - RJ, Agosto de 2007. Disponível em: 
http://www.bdtd.ndc.uff.br/tde_busca/arquivo.php?codArquivo=2194 Acessado em 25/01/2009.

SANTOS, João Marcos Leitão. Educação na Paraíba Colonial: O período holandês.

Mnemosine Revista. UFCG, Campina Grande, PB, n.1, V.1, Janeiro/junho de 2010.

SCHAMA, Simon. O desconforto da riqueza, a cultura holandesa na Era de Ouro. São Paulo, SP, Companhia das letras, 1992.

SCHALKWIJK, Frans Leronard. Igreja e Estado no Brasil Holandês (1630 - 1654). $3^{\text {a }}$ Edição. São Paulo. Cultura Cristã 2004. . Índios evangélicos no Brasil Holandês. Fides Reformata, Vol 2, n1, São Paulo, SP, 1997.

SILVESTRE, Armando Araújo. Calvino e a Resistência ao Estado. São Paulo - SP, Editora Mackenzie, 2003.

SOUZA, Laura de Mello. O diabo e a terra de Santa Cruz. São Paulo, SP. Companhia das Letras, 2006

TODOROV, Tzvetam. A conquista da América, a questão do outro. São Paulo, SP, Martins Fontes, 1998.

VAINFAS, Ronaldo. A Heresia dos Índios - Catolicismo e Rebeldia no Brasil Colonial. São Paulo - SP, Companhia das Letras, 2006.

. Jerusalém Colonial. Rio de Janeiro, Civilização Brasileira, 2010

VIRAÇÃO, Francisca Jaquelini de Souza. A Igreja Potiguara: A saga dos índios protestantes no Brasil Holandês. Revista Historiar, Ano II, nº, 2010, pág. 8 - 26. 
. A primeira Igreja Protestante do Brasil: Igreja

Reformada Potiguara (1625 - 1692). São Paulo, Ed. Mackenzie, 2013

VOVELLE, Michel. Ideologias e Mentalidades. $2^{\mathrm{a}}$ Ed. São Paulo - SP, Editora Brasiliense, 2004.

WOLKMER, Antônio Carlos. Cultura Jurídica Moderna, humanismo renascentista e Reforma Protestante. Revista Seqüência, no 50, p. 9-27, jul. 2005.

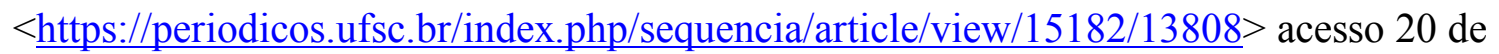
Agosto de 2015

ARTIGO ENVIADO EM: 24/06/2017 ARTIGO ACEITO PARA PUBLICAÇÃO EM: 01/11/2017 